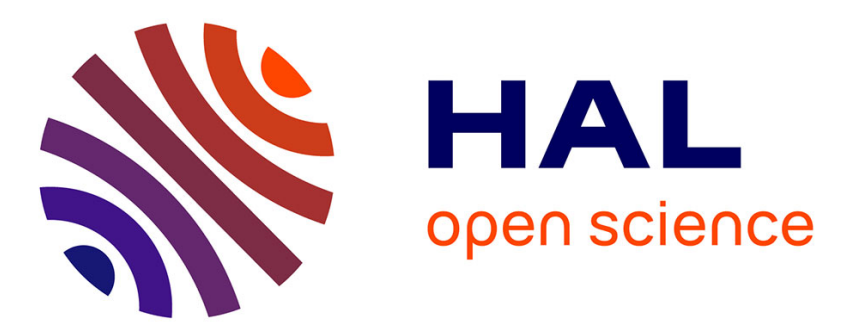

\title{
Dynamic generation of dilemmas in virtual learning environments for non-technical skills training
} Azzeddine Benabbou, Domitile Lourdeaux, Dominique Lenne

\section{To cite this version:}

Azzeddine Benabbou, Domitile Lourdeaux, Dominique Lenne. Dynamic generation of dilemmas in virtual learning environments for non-technical skills training. 15th IEEE International Conference on Cognitive Informatics and Cognitive Computing (ICCI*CC 2016), Aug 2016, Palo Alto CA, United States. pp.231-234. hal-01403483

\section{HAL Id: hal-01403483 https://hal.science/hal-01403483}

Submitted on 26 Nov 2016

HAL is a multi-disciplinary open access archive for the deposit and dissemination of scientific research documents, whether they are published or not. The documents may come from teaching and research institutions in France or abroad, or from public or private research centers.
L'archive ouverte pluridisciplinaire HAL, est destinée au dépôt et à la diffusion de documents scientifiques de niveau recherche, publiés ou non, émanant des établissements d'enseignement et de recherche français ou étrangers, des laboratoires publics ou privés. 


\title{
Dynamic generation of dilemmas in virtual learning environments for non-technical skills training
}

\author{
Azzeddine Benabbou, Domitile Lourdeaux and Dominique Lenne \\ CNRS, Heudiasyc UMR 7253 \\ Sorbonne Universités, Université de Technologie de Compiègne \\ Compiègne, France \\ \{azzeddine.benabbou, domitile.lourdeaux, dominique.lenne\}@ hds.utc.fr
}

\begin{abstract}
Critical situations are situations where a complementarity between technical and non-technical skills is crucial. Several critical dimensions characterize them. In order to train for such situations, simulation systems have to be able to generate scenarios where these dimensions are present in order to solicit one or several non-technical skills. In this paper we focus on one particular critical dimension which is the "Dilemma". We present our approach for dynamically generating dilemma-based situations using activity and causality models.
\end{abstract}

Keywords-Dilemma; Virtual Environment; Non-technical skills; Training simulation; Orchestration

\section{INTRODUCTION}

In order to prevent disastrous consequences from happening, operators have to be trained to handle complex and critical situations. While training for "normal" situations (taking care of a baby, manufacturing an engine...) in genuine conditions can be an easy exercise to reproduce, training for critical situations (plane crash, terrorist attack, gas leak...) represent some serious challenges since reproducing them is complicated, if not impossible. Virtual reality comes to tackle this issue. It enables the systems to simulate such complex and critical situations especially when cost, accessibility and dangerousness prevent learners from being put in genuine situations.

A critical situation can be defined as a complex and dynamic situation, often unexpected and difficult to anticipate. To handle it, technical skills are far from being the only asset needed. Several studies [1] have shown that more than $70 \%$ of medical errors are due to issues related to one non-technical skill or more. Thus, besides training for technical medical procedures, medical staff needs to develop another kind of skills such as "situation awareness", "decision making", "communication" etc. It is in that vein that the project MacCoy Critical is born. The goal of the project is to study and improve training systems that use simulation and virtual environments especially for nontechnical skills training in critical situations. The fields targeted by the project are vehicle driving and health.

Training in complex environments is not only a difficult task for the learner but it is also challenging for the instructor; to assure freedom of action of the learner and to maintain a pedagogical control on the simulation, the instructor has to anticipate all the possible actions. This can be done easily by scripting the behavior of the system. As far as complex situations are concerned this solution is out of order, as it will lead to combinatorial explosion. Given all this, we believe that the dynamic generation and control of the situations are crucial features that a simulation system for training in complex situations must have. In this paper we discuss about our work in dynamic generation of situations, especially the control of their criticality by generating dilemmas; in section II, we list some critical dimensions identified by the means of field analysis and interviews with experts and ergonomists in the project. Then in section III, we discuss about the use of dilemmas in education and also about ethical dilemmas in healthcare. In section IV, we present a quick state of the art of the simulation systems that include dilemma-based situations. Finally, in section V, we introduce our simulation platform and finally we expose our approach of dilemma generation.

\section{CRITICAL DIMENSIONS}

Our purpose is to train for non-technical skills in critical situations. In order to bring out some critical dimensions that define a critical or a potential critical situation, the first thing we had to do was to analyze the notion of criticality. In risk assessment, the criticality is a numerical value calculated from several parameters, which are often: severity (of the event) and probability (of the event occurring). Besides these parameters, we have identified other critical dimensions, by means of field analysis and interviews with instructors and ergonomists, which play an important role in non-technical skills training. These dimensions are also considered descriptors of situations that could become critical. These dimensions are:

- Ambiguity; situation where there is doubtfulness of meaning or intentions (e.g. road markings in contradiction with vertical road signs).

- Dilemma: situation where a difficult choice has to be made knowing that there is no good solution and that whatever is the choice, negative consequences will occur and/or one or more human value will be sacrificed.

- Socio-cognitive load: situation where a person is affected by several external factors such as time restriction, social pressure, stress produced by other characters' behaviors, multiplicity of the tasks he/she has to accomplish..

- Newness: a situation that was never met before. 
- Learner's ability: the learner has not the skills to handle the situation.

Some of these dimensions are intrinsic to the situation while others depend on the learner's profile which is dynamically updated (the learner's profile is not discussed in this paper). There are also dimensions that can both be intrinsic and learner- related. Besides, we propose a distinction is made between the dimensions that are informed in advance by the instructors, those which are dynamically calculated and generated during the simulation and those which can both be generated dynamically and informed in advance by instructors (Table 1). In this paper we will focus on one particular critical dimension: "dilemma".

Table 1: Critical dimensions

\begin{tabular}{|l|c|c|l|l|}
\hline \multicolumn{1}{|c|}{ Dimensions } & Situation-related & Learner-related & \multicolumn{1}{c|}{ Nature } & \multicolumn{1}{c|}{ Calculation } \\
\hline Ambiguity & $\mathrm{x}$ & & Boolean & In advance/ dynamic generation \\
\hline Dilemma & $\mathrm{x}$ & $\mathrm{x}$ & Nominal & Dynamic generation \\
\hline Frequency of occurrence & $\mathrm{x}$ & & Ordinal/interval & In advance/ dynamic generation \\
\hline Severity & $\mathrm{x}$ & & Ordinal/interval & In advance \\
\hline Socio-cognitive load & $\mathrm{x}$ & & Mixed & In advance/ dynamic generation \\
\hline Newness & & $\mathrm{x}$ & Boolean & Dynamic generation \\
\hline Learner's ability & & $\mathrm{x}$ & Mass of belief & Dynamic generation \\
\hline
\end{tabular}

\section{DILEMMA AND EDUCATION}

In this section we discuss about the use of dilemmas in education for the moral development and also about the importance of training for dilemma situations the healthcare field

\section{A. Moral development method}

Lawrence Kohlberg, one of the most eminent psychologists of the $20^{\text {th }}$ century [7], is known for his stages of moral development theory. The theory says that moral reasoning has six developmental stages grouped into three levels. Kohlberg conducted his studies on individuals by exposing them to moral dilemmas. "Heinz dilemma" is the most famous one. The psychologist was interested in the way the individuals justified their answers, and the reasoning behind their choices. The answer itself was not as important as their explanations. This method has inspired didactic instructors such as Jean-Marie Debunne, the creator of the game "Debunne", who conceived the moral education program for secondary school in Québec (1985 - 2005). The Ministry of National Education in France has also adopted the Kohlberg Method. It was recently introduced into the "Moral and Civic Education" course ${ }^{2}$.

\section{B. Ethical dilemmas in healtcare} are confronted to situations where they have to make difficult choices. These choices are complicated because, in most of the cases, there is a conflict of values. Besides, there
The nurses face ethical dilemmas on a daily basis. They

is no "right" solution to an ethical dilemma. If the nurses (or the medical staff in general) are not trained for handling such situations, they are likely to be destabilized when the time comes. Marie-Anne Lecomte listed in her article [8] several reasons why the nurses should be trained to face ethical dilemma. For example, being able to step back and look at the overall picture before taking a decision, improving the relation between the patient and the caregiver, being able to argue, negotiate and make compromises... The author talked also about the "ethical competence" which is "skill" that the nurses must acquire to handle ethical dilemmas. She said that they start to build this competence during the basic training (awareness), and improve it during their professional career (experience). Simulation and virtual reality can contribute to this development by offering the learner's the opportunity to be trained to face such situations by simulating scenarios with ethical dilemmas.

\section{RELATED WORK}

Playing the role of a U.S. Army lieutenant, a human user finds himself facing a difficult situation. The lieutenant has to choose between sending his troop to help his platoon downtown or to secure a landing zone for a medevac helicopter in order to assist a local boy in a critical situation which was in a civilian vehicle crashed by one of the platoon's vehicles. This dilemma situation was implemented by [2] in an Army peacekeeping scenario. In medical field, [3] models the behavior of a doctor in a situation where he is confronted to a complicated choice:

\footnotetext{
${ }^{1}$ Heinz's wife was dying. A local chemist discovered a new drug that could save Heinz's wife. The drug was too expensive, that he could not afford it. The local chemist refused any kind of arrangement with Heinz, saying he had
}

discovered the drug and he is going to make money from it. Should Heinz steal the drug to save his wife?

${ }^{2}$ http://eduscol.education.fr/cid92404/methodes-etdemarches. html 
administrating large doses of morphine to his dying patient to reduce the pain but in the same time hastening his death, or prolonging his "painful" life. The common point about the dilemma situations above is that they are totally or partially scripted, it means that the scenario is designed in advance and not dynamically generated. In the literature, we can point out the works of [4] who proposed a user model for a system which automatically generates stories based on dilemmas. The dilemma generation process takes into consideration the relations between characters in order to identify which type of dilemma to put in place. Five types where identified: Betrayal, Sacrifice, Greater Good, Take Down and Favor.

Our approach is slightly different. Our purpose is to dynamically generate the situations where there is a conflict of values in general (not necessarily involving more than one character) and/or contradictory knowledge leading to difficultchoice-making situations.

\section{GENERATION OF DILEMMA-BASED SITUATIONS}

\section{A. HUMANS platform: Dynamic generation of pedagogical situations}

In this section, we will present our current platform, dedicated to the simulation of virtual environments within complex domains where human factors are critical.

The platform [10] is composed of an orchestration module (TAILOR [9]) among others. This module is responsible of generating and selecting situations according to the learner's profile. It is also an operationalization of the Zone of Proximal Development (ZPD) [5]. This zone is defined as the distance between the current development level of a person (ability to solve problems alone) and the potential development level that can be reached with assistance. We believe that this assistance is not necessarily personified and this role can be fulfilled by a computer system, in this case, our orchestration system. According to the beliefs that the system has on the learner's ability to handle a class of situations, it can determine the ZPD of the user and thus chooses to direct the simulation towards situations inside or outside this zone.

The classes of situations are represented in a multidimensional space. The dimensions are descriptors that can be cognitive variables (patient gender, size of the lesion ...), skills or tasks. In regard of pedagogical objectives and taking into consideration the ZPD, the orchestration module chooses a class of situation from this space. Then it computes the activity and/or the causality model to identify the task's preconditions and/or events needed to initialize the scene with all the elements needed for the situation. The platform's modules use three models world, activity and causality:

World is composed of a static (ontology) and dynamic (rules) description of the world (objects, objects' behavior, possible actions...);

Activity is a hierarchical representation of the tasks. Each task can have preconditions (e.g. task: \{Verb: "Stop", Precondition: "red light is on" $\}$ ) and can be tagged;

Causality is an acyclic graph that expresses pertinent causal chains occurring in the environment. It also includes barriers that prevent an event from occurring or protect from its consequences (e.g. "Heavy bleeding" $\rightarrow$ "Passing out"; Prevention barrier: "Treat bleeding")

\section{B. Dynamic Generation of dilemma-based situations}

In the literature there is different types of dilemmas (moral, ethical, social...). In our approach we classify them according to the way they are computationally generated. We propose the following dilemma categories:

1. Situations where the learner has to perform two contradictory tasks;

2. Situations where the learner has to make a choice where there is an opposition of moral values;

3. Situations where there is no opposition of moral values but consequences are negative anyway (e.g. a killer who asks a mother which one of her twin sons she wants him to kill. If no choice is made, they are both going to die).

Let us now suppose that during the simulation, the diagnosis process decided that we need to verify the learner's ability to "make decision" (non-technical skill) in dilemma situations. This instruction is given as an input to the orchestration engine, which is going to look for tasks $T$ that involve "making decision" skill. The orchestration engine would normally select one task $t$, and the situation would be generated using the task preconditions. As far as dilemmas are concerned we propose to slightly change this behavior by handling the tasks $T$ before the selection process. We propose to search for contradictory tasks in $T$ and generate a set of pairs $C T$ of contradictory tasks. A pair of tasks is then selected and finally a situation is generated using their preconditions (See Algorithm 1).

Example: After applying Algorithm 1 on the activity model, it returns the following pair of contradictory tasks (the task representation is simplified for the sake of example):

(task1: \{Verb: “Brake”, Preconditions: "Red light is on”\}) (task2; \{Verb: "Do not brake”, Preconditions: "Vehicle aquaplaning”')

Taking into consideration the preconditions, the orchestration/causal engine will then try to cause an aquaplaning when the vehicle is close to a red light.

The dilemma in this situation is that the driver should brake and stop because he must respect the law, but if he does, he risks losing control of his vehicle.

This type of dilemma can also be generated using the human barriers of the causality model instead of the tasks of the activity model (Algorithm 2).

As far as the second type of dilemma is concerned we propose to generate the situations using almost the same algorithm used for the first type. Instead of looking for contradictory tasks, we search for tasks which produce a conflict between two human values. We remind that in the activity model, we can tag the tasks. These tags can be utilized to specify which human value is concerned if the task is accomplished (e.g. task: "avenge the father" tag: "honor"). To identify two conflicting human values we believe that the 
theory of Basic Universal Human Values [6] could be a serious track to consider. This theory recognizes ten universal human values represented in a circular structure and describes the dynamic relations between them.

Algorithm 1 Search for contradictory tasks in the activity model for dilemma generation.

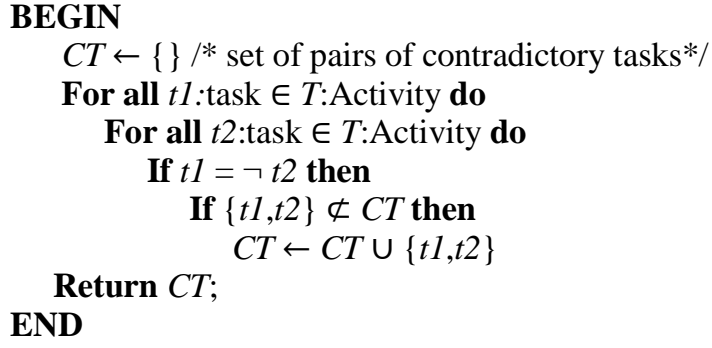

The third type of dilemma is a situation where the consequence of the choice is always negative and the same. To generate this type, we propose to use the causality model. The system needs to find two events with the same protection barrier which leads to the same negative event.

Example (The following causality representation is simplified for the sake of example):

- ("John is threatened by the killer" $\rightarrow$ "John is dead"; Barrier: "The mother chooses him")

- ("Brad is threatened by the killer" $\rightarrow$ "Brad is dead"; Barrier: "The mother chooses him")

- (("John is dead" OR "Brad is dead") $\rightarrow$ "The mother loses her son").

Algorithm 2 Search for contradictory barriers in the causality model for dilemma generation.

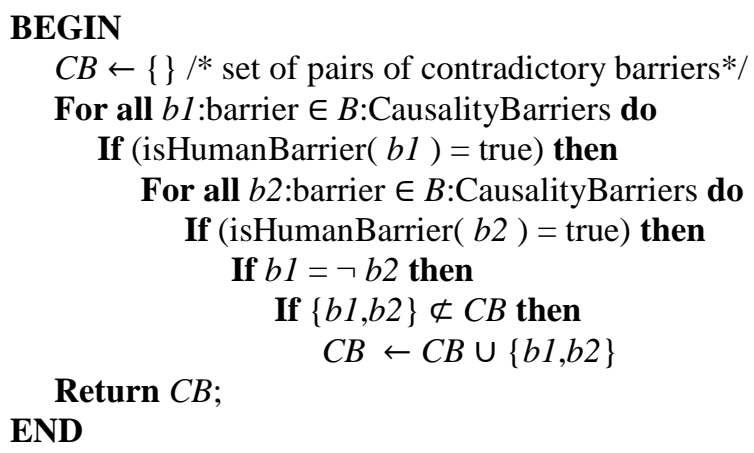

\section{CONCLUSION}

In complex environments, manually generating relevant situations requires a huge amount of work especially if the learner's actions have to be taken into consideration. Our work is focused on dynamical generation of situations with critical dimensions in order to solicit one or several non-technical skills. In this paper we presented our approach for generating one of these dimensions: the dilemma.
The originality of our approach is the dynamic generation of this kind of situations and the consideration of values conflict and contradictory knowledge. We identified three types of dilemma-based situations and proposed two algorithms for the generation. To go further in our approach, we need to design an efficient articulation between the activity and the causality model in the generation process, in order to determine when one of these models is more efficient than the other. Also, we intend to use probabilities in the causality model. This could be taken into consideration to decide which dilemma to present to the user according to the probability of occurrence of the events.

\section{ACKNOWLEDGMENT}

The authors want to thank the French National Research Agency (ANR) for the funding of the MacCoy Critical project (ANR-14-CE24-0021), as well as all the members of the consortium : IFSTTAR, LIG Université Joseph Fourier Grenoble, Sorbonne Universités - Université de technologie de Compiègne - CNRS - Heudiasyc UMR 7253, Université Pierre et Marie Curie - LIP6, LATI and ILUMENS Université Paris Descartes, Medusims.

\section{REFERENCES}

1. Mitchell, L. Flin, R. \& Mitchell, L.(Eds)(2009). Safer surgery: analysing behaviour in the operating theatre. Farnham: Ashgate.

2. Jeff Rickel, Stacy Marsella, Jonathan Gratch, Randall Hill, David Traum and Bill Swartout, "Towards a New Generation of Virtual Humans for Interactive Experiences," in IEEE Intelligent Systems July/August 2002, pp. 32-38

3. Jonathan Gratch and Stacy Marsella, "A Domain-independent framework for modeling emotion, " Journal of Cognitive Systems Research, Volume 5, Issue 4, 2004, pp. 269-306

4. Barber, H., \& Kudenko, D. (2007, June). A user model for the generation of dilemma-based interactive narratives. In Workshop on Optimizing Player Satisfaction at AIIDE (Vol. 7).

5. Vygotsky, L. S. (1980). Mind in society: The development of higher psychological processes. Harvard university press.

6. Schwartz, S. H. (2006). Les valeurs de base de la personne: théorie, mesures et applications. Revue française de sociologie, 47(4), 929-968.

7. Haggbloom, S. J., Warnick, R., Warnick, J. E., Jones, V. K., Yarbrough, G. L., Russell, T. M., ... \& Monte, E. (2002). The 100 most eminent psychologists of the 20th century. Review of General Psychology, 6(2), 139.

8. Lecomte, M. A. (2006). La formation à l'éthique des étudiants en soins infirmiers (Belgique). Recherche en soins infirmiers, (3), 423.

9. Carpentier, K., \& Lourdeaux, D. (2013). Generation of learning situations according to the learner's profile within a virtual environment. In Agents and Artificial Intelligence (pp. 245-260). Springer Berlin Heidelberg.

10. Barot, C., Lourdeaux, D., \& Lenne, D. (2013, July). Using planning to predict and influence autonomous agents behaviour in a virtual environment for training. In Cognitive Informatics \& Cognitive Computing (ICCI* CC), 2013 12th IEEE International Conference on (pp. 274-281). IEEE. 